\title{
Broadband DR antenna made of high-Q ceramic
}

\author{
Yu-Ching Huang ${ }^{\mathrm{a}}$, Ming-Chung $\mathrm{Wu}^{\mathrm{a}}$, Tze-Hsuan Chang ${ }^{\mathrm{b}}$, \\ Jean-Fu Kiang ${ }^{\mathrm{b}}$, Wei-Fang $\mathrm{Su}^{\mathrm{a}, \mathrm{c}, *}$ \\ a Department of Materials Science and Engineering, National Taiwan University, Taipei, Taiwan \\ ${ }^{\mathrm{b}}$ Department of Electrical Engineering and Graduate Institute of Communication Engineering, \\ National Taiwan University, Taipei, Taiwan \\ ${ }^{\mathrm{c}}$ Center for Condensed Matter Sciences, National Taiwan University, Taipei, Taiwan
}

Available online 4 January 2007

\begin{abstract}
In this work, different sizes and shapes of notched dielectric resonator antennas (DRAs) made of low-loss, high-permittivity ceramic are fabricated for broadband applications. Special-formulated glue is used to fabricate notched DRAs from different $\mathrm{Zn}_{3} \mathrm{Nb}_{2} \mathrm{O}_{8}$ parts. The sintered $\mathrm{Zn}_{3} \mathrm{Nb}_{2} \mathrm{O}_{8}$ parts are prepared by using $\mathrm{Zn}_{3} \mathrm{Nb}_{2} \mathrm{O}_{8}$ powder and small amount $(\sim 0.1 \mathrm{wt} \%)$ of polyvinyl alcohol (PVA) which is imperative to have high densification and good dielectric properties of $\mathrm{Zn}_{3} \mathrm{Nb}_{2} \mathrm{O}_{8}$. The assembled DRA is fed through an aperture, which also serves as a slot antenna. The 10-dB bandwidth of the DRA is about $24 \%$.
\end{abstract}

(C) 2006 Elsevier Ltd. All rights reserved.

Keywords: Sintering; Shaping; Dielectric properties; Dielectric resonator; Electrical properties

\section{Introduction}

With the rapid growth of global microwave communication in recent years, the demand for high-quality microwave devices has increased. ${ }^{1,2}$ Numerous dielectric materials have been developed, for example, zinc-containing ceramics such as $\mathrm{Zn}_{3} \mathrm{Nb}_{2} \mathrm{O}_{8}$, are good candidates for microwave dielectric devices owing to its high-quality factor and relatively low temperature to achieve high density. ${ }^{3-8}$ Dielectric resonator antenna (DRA) made of low-loss materials can have high efficiency in the millimeterwave band in which the ohmic loss becomes significant. ${ }^{9}$ Various types of radiation pattern are available by exciting different resonant modes. Their impedance bandwidth can be increased by using different approaches. ${ }^{8-12}$

The effect of adding small amount of polyvinyl alcohol (PVA) into $\mathrm{Zn}_{3} \mathrm{Nb}_{2} \mathrm{O}_{8}$ powders is also investigated. A special-formula glue is used to fabricate different sizes and shapes of notched DRAs from different $\mathrm{Zn}_{3} \mathrm{Nb}_{2} \mathrm{O}_{8}$.

\footnotetext{
* Corresponding author at: Department of Materials Science and Engineering, National Taiwan University, Taipei, Taiwan. Tel.: +866 2 33664078; fax: +866233664078 .

E-mail address: suwf@ntu.edu.tw (W.-F. Su).
}

\section{Experiments}

The raw materials are reagent-grade oxide powder of $\mathrm{ZnO}$ and $\mathrm{Nb}_{2} \mathrm{O}_{5}$ (both have $99.9 \%$ purity, Alfa Chemical, USA). The $\mathrm{Zn}_{3} \mathrm{Nb}_{2} \mathrm{O}_{8}$ powder is prepared using conventional mixing solid method with an appropriate molar ratio and calcined at $1050{ }^{\circ} \mathrm{C}$ for $2 \mathrm{~h}$. The crystalline phase of calcined $\mathrm{Zn}_{3} \mathrm{Nb}_{2} \mathrm{O}_{8}$ powder is confirmed with the literature data. ${ }^{7}$ The calcined powder is granulated by adding PVA, in comparison with the powder without adding PVA (non-granulated).

The calcined powder is characterized by light scattering (Mastersizer 2000, Malvern Instruments, UK) for particle size, B.E.T. for specific surface area (Micromeritics, ASAP2000 BET, USA), and X-ray diffractometer (XRD, PW 1830, Philips, the Netherlands) for the crystalline structure. The $\mathrm{Zn}_{3} \mathrm{Nb}_{2} \mathrm{O}_{8}$ powder is pressed at $5 \times 10^{6} \mathrm{~kg} \mathrm{~m}^{-2}$ to form tablets $(8 \mathrm{~mm}$ in diameter) and sintered at different temperatures for $4 \mathrm{~h}$.

The density of the sintered $\mathrm{Zn}_{3} \mathrm{Nb}_{2} \mathrm{O}_{8}$ tablets is measured using the Archimedes' method. The dielectric properties of the sintered tablets are evaluated by using network analyzer (8722ES, Hewlett Packard, USA). The microstructures of the sintered samples are evaluated by using scanning electron microscopy (SEM) equipped with energy dispersive spectrometer (Philips, XL-30, the Netherlands). 


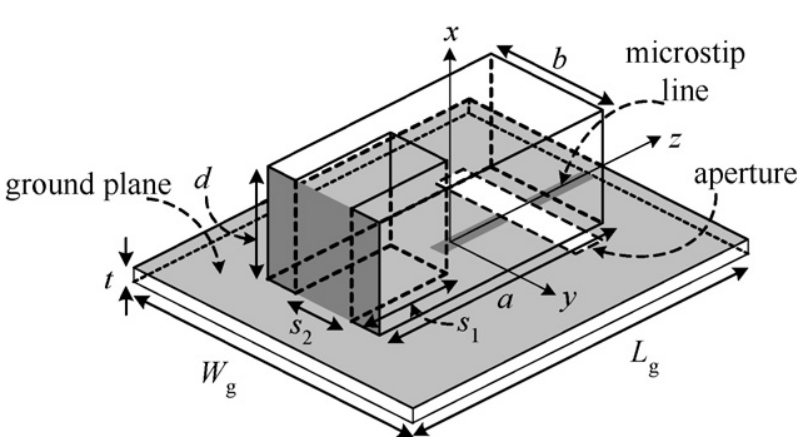

Fig. 1. Configuration of notched DRA.



Fig. 2. XRD patterns of $\mathrm{Zn}_{3} \mathrm{Nb}_{2} \mathrm{O}_{8}$ powders calcined at different temperatures.
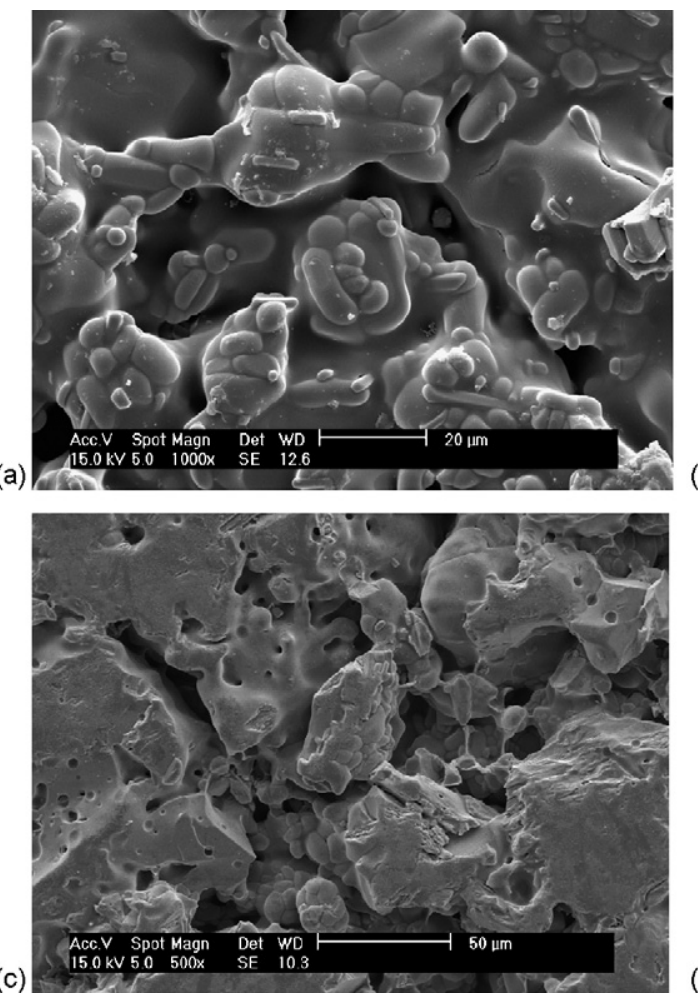

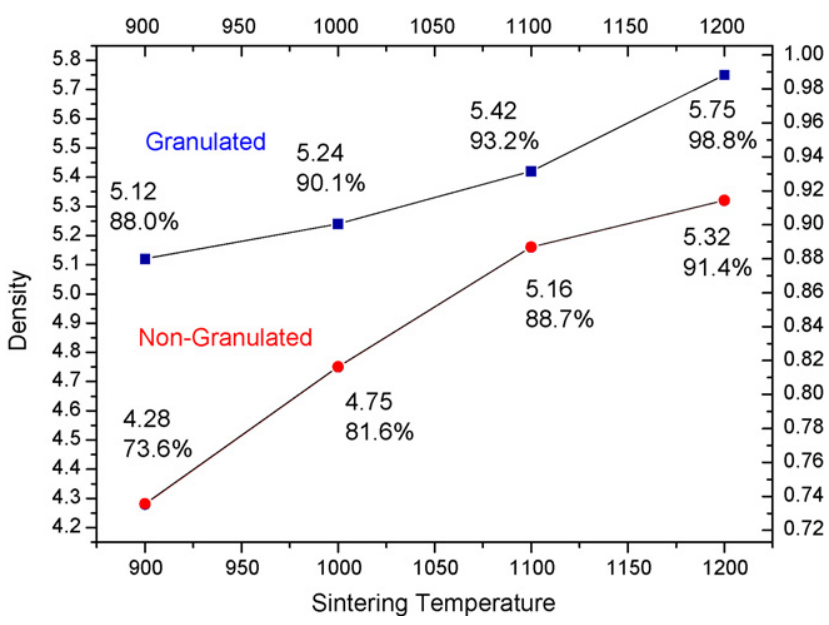

Fig. 3. Different densities of tablet sintered at different temperatures.

To fabricate DRA parts, different formulas of $\mathrm{Zn}_{3} \mathrm{Nb}_{2} \mathrm{O}_{8}$ slurry are prepared. By changing the relative weight percentage of binder (polyvinyl butyral) and dispersant (polyoxyethylene nonyl phenyl ether), the most suitable formula is found.

Fig. 1 shows the panoramic schematic of the assembled notched DRA, which is placed on an FR4 substrate, fed by a microstrip line through an aperture. By tuning the aperture size and the length of the microstrip line, the input impedance can be properly matched. Its return loss is measured by using an HP network analyzer, and its radiation pattern is measured in an anechoic chamber.

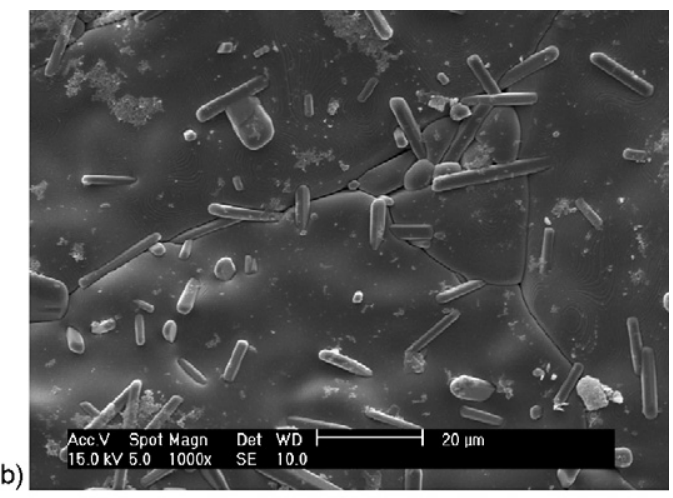

(d)

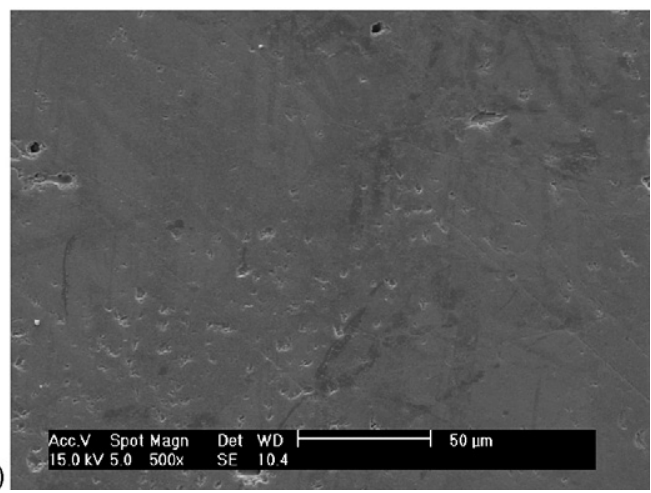

Fig. 4. SEM surface and inner structures of sintered tablets: (a) non-granulated surface structure, (b) granulated surface structure, (c) non-granulated inner structure and (d) granulated inner structure. 
Table 1

Properties of two calcined $\mathrm{Zn}_{3} \mathrm{Nb}_{2} \mathrm{O}_{8}$ powders with or without PVA

\begin{tabular}{lcll}
\hline Sample & $\begin{array}{l}\text { Zeta potential } \\
(\mathrm{mV})\end{array}$ & $\begin{array}{l}\text { Particle } \\
\text { size }(\mu \mathrm{m})\end{array}$ & $\begin{array}{l}\text { Surface area } \\
\left(\mathrm{m}^{2} / \mathrm{g}\right)\end{array}$ \\
\hline $\mathrm{Zn}_{3} \mathrm{Nb}_{2} \mathrm{O}_{8}$ (with PVA) & 20.13 & 1.13 & 3.16 \\
$\mathrm{Zn}_{3} \mathrm{Nb}_{2} \mathrm{O}_{8}$ (without PVA) & -32.77 & 0.85 & 3.53 \\
\hline
\end{tabular}

Table 2

Microwave dielectric properties of $\mathrm{Zn}_{3} \mathrm{Nb}_{2} \mathrm{O}_{8}$ sintered disks at $120{ }^{\circ} \mathrm{C}$ for $4 \mathrm{~h}$

\begin{tabular}{llll}
\hline Sample & $K$ & $Q \times f(\mathrm{GHz})$ & $f_{\mathrm{o}}(\mathrm{GHz})$ \\
\hline $\mathrm{Zn}_{3} \mathrm{Nb}_{2} \mathrm{O}_{8}$ (non-granulated) & 17.89 & 55,500 & 8.00 \\
$\mathrm{Zn}_{3} \mathrm{Nb}_{2} \mathrm{O}_{8}$ (granulated) & 19.55 & 70,600 & 8.83 \\
\hline
\end{tabular}

\section{Results and discussion}

The $\mathrm{Zn}_{3} \mathrm{Nb}_{2} \mathrm{O}_{8}$ is prepared with the solid mixing method. The powder is calcined at $900,1000,1050$ and $1100^{\circ} \mathrm{C}$, respectively. The individual crystalline structure of the calcined powder is measured by XRD. As shown in Fig. 2, a pure single-phase of $\mathrm{Zn}_{3} \mathrm{Nb}_{2} \mathrm{O}_{8}$ is formed under $1050^{\circ} \mathrm{C}$, and there are other phases, $\mathrm{ZnO}$ and $\mathrm{Zn}_{1} \mathrm{Nb}_{2} \mathrm{O}_{6}$, calcined below $1050^{\circ} \mathrm{C}$. Therefore, all $\mathrm{Zn}_{3} \mathrm{Nb}_{2} \mathrm{O}_{8}$ powders are calcined at $1050^{\circ} \mathrm{C}$.

The basic properties of $\mathrm{Zn}_{3} \mathrm{Nb}_{2} \mathrm{O}_{8}$ series are listed in Table 1 . The differences between granulated powder and non-granulated are indicated in zeta potential, particle size and surface area. We can observe the difference between the two series of powder from the values of zeta potential which is due to the PVA powder cohering on the $\mathrm{Zn}_{3} \mathrm{Nb}_{2} \mathrm{O}_{8}$ particles. The densification of sintered tablets under different temperatures is shown in Fig. 3. The SEM photos of the sintered tablets in Fig. 4 also show the disparity in the densification. The granulated powder has higher densification than the non-granulated one. The densification of



Fig. 5. Return loss of the DRA, $a=11.7 \mathrm{~mm}, b=18 \mathrm{~mm}, d=5 \mathrm{~mm}$, permittivity $=20, s_{1}=5 \mathrm{~mm}, s_{2}=8 \mathrm{~mm}, L_{\mathrm{s}}=4 \mathrm{~mm}, w_{\mathrm{m}}=1.15 \mathrm{~mm}, t=0.6 \mathrm{~mm}$, $W_{\mathrm{a}}=2 \mathrm{~mm}, L_{\mathrm{a}}=14 \mathrm{~mm}, d_{\mathrm{s}}=6 \mathrm{~mm}, W_{\mathrm{g}}=L_{\mathrm{g}}=60 \mathrm{~mm}$. sintered tablets also affects the microwave dielectric properties. As shown in Table 2, better dielectric properties appear at higher densification.

To fabricate different sizes and shapes of notched DRAs, sintered ceramics parts of rectilinear shape are glued with special-formula glue which is contained with $\mathrm{Zn}_{3} \mathrm{Nb}_{2} \mathrm{O}_{8}$ calcined powders, binder and dispersant. The $\mathrm{Zn}_{3} \mathrm{Nb}_{2} \mathrm{O}_{8}$ powders dispersed in the glue are used as sintering agent between two ceramics. Binder and dispersant are added to increase the viscosity and make the powders disperse well. The proportion among these compounds is adjusted to find the best coherence. The best formula contains $77.82 \%$ of powder, $19.46 \%$ of binder, and $2.72 \%$ of dispersant.

Fig. 5 shows the measured and simulated return losses of the notched DR antenna, which match reasonably well. The
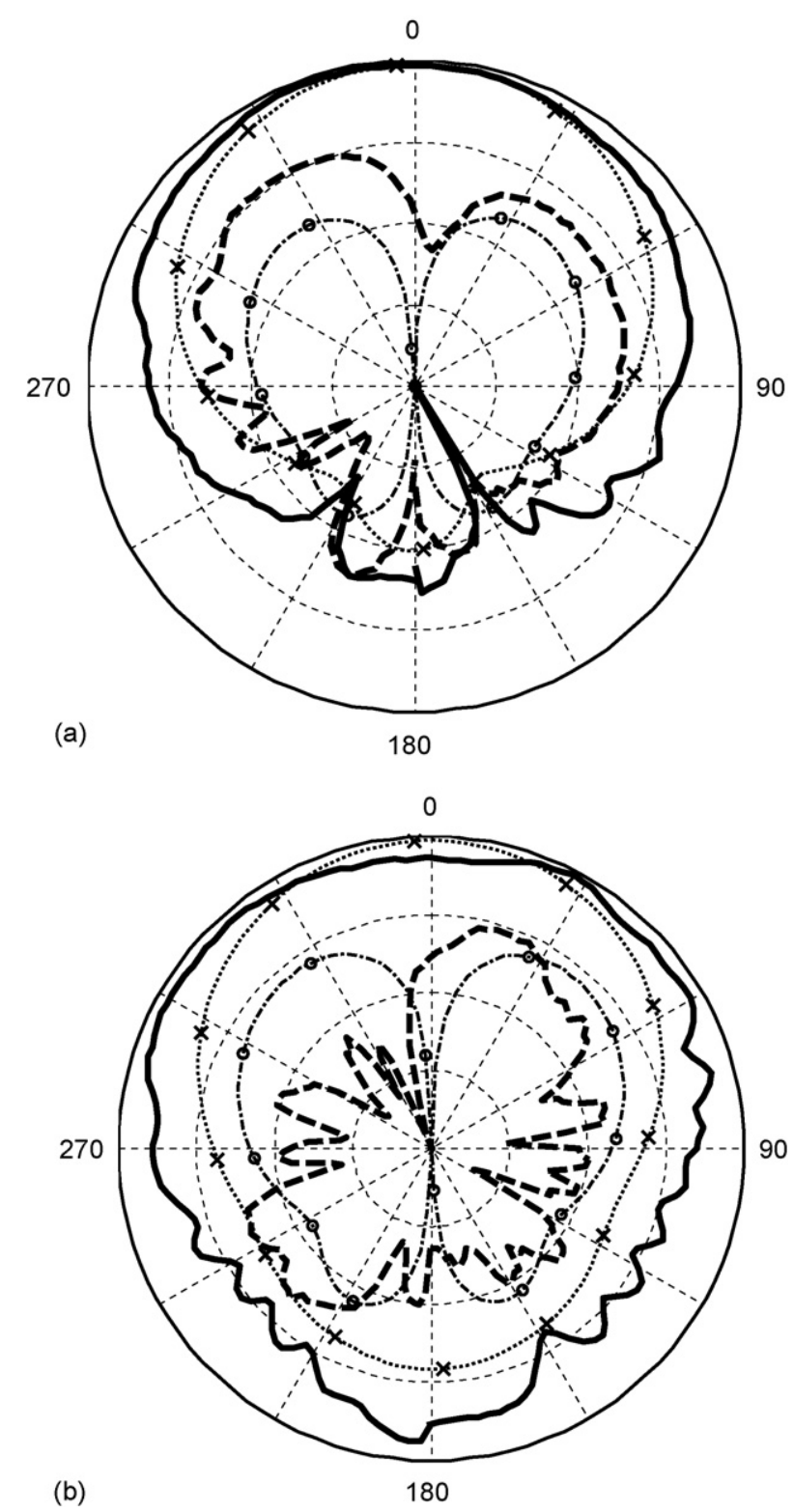

Fig. 6. Radiation pattern of the DRA on the $x y$-plane, all parameters are the same as in Fig. 5, (a) $f=5.34 \mathrm{GHz}$, (b) $f=5.74 \mathrm{GHz},(--)$ measured $E_{\theta},(-\cdot-)$ measured $E_{\varphi},(\cdot \times \cdot)$ simulated $E_{\theta},(\cdot-\bigcirc-\cdot)$ simulated $E_{\varphi}$. 
$10-\mathrm{dB}$ impedance bandwidth is about $24 \%(5.12-6.52 \mathrm{GHz})$, which can cover the IEEE 802.11 a specification. The bandwidth is achieved by merging the resonant frequencies of the $\mathrm{TE}_{111}$ and the $\mathrm{TE}_{211}$ modes, respectively. The efficiency of the DRA is nearly $100 \%$ due to the high-Q factor of the ceramics. Fig. 6 shows the radiation pattern of the DRA. The direction along $x$ axis is marked $0^{\circ}$ in the patterns. The $E_{\theta}$ component on the $x y$ plane is nearly omnidirectional at the broadside direction with bandwidth of $120^{\circ}$, which suggests that this DRA can be used as a sectional antenna at the access point. The antenna gain is about $5.1 \mathrm{dBi}$ at $f=5.53 \mathrm{GHz}$. Note that a $3 \mathrm{~dB}$ difference between simulation and measurement results around the beam edge is normal.

\section{Conclusion}

Broadband DR antenna has been made using high-Q ceramic. Addition of PVA can improve the densification of sintered ceramics and improve the $Q \times f$ factor to $70,000 \mathrm{GHz}$. The 10 $\mathrm{dB}$ impedance bandwidth of a notched DR antenna made of such ceramics can be increased to about $24 \%(5.12-6.52 \mathrm{GHz})$, with the $E_{\theta}$ pattern nearly omnidirectional over the bandwidth.

\section{Acknowledgements}

Financial support obtained from the National Science Council of Republic of China (NSC-94-2120-M-002-010) is highly appreciated.

\section{References}

1. Wakine, K., Recent development of dielectric resonator materials and filters in Japan. Ferroelectrics, 1989, 91, 69-86.

2. Wilcox Sr., D., Huang, R. F. and Dai, S. X., Enabling materials for wireless. Multilayer ceramic integrated circuit (MCIC) applications. Ceram. Trans., 1999, 97, 201-213.

3. Kim, D. W., Ko, K. H. and Hong, K. S., Influence of copper (II) oxide additions to zinc niobate microwave ceramics on sintering temperature and dielectric properties. J. Am. Ceram. Soc., 2001, 84(6), 1286-1290.

4. Kim, D. W., Kim, J. H., Kim, J. R. and Hong, K. S., Phase constitutions and microwave dielectric properties of $\mathrm{Zn}_{3} \mathrm{Nb}_{2} \mathrm{O}_{8}-\mathrm{TiO}_{2}$. Jpn. J. Appl. Phys. 2001, 40, 5994-5998.

5. Kong, L. B., Ma, J., Huang, H., Zhang, R. F. and Zhang, T. S., Zinc niobate derived from mechanochemically activated oxides. J. Alloys Compd., 2002, 347, 308-313

6. Su, W. F. and Lin, S. C., Interfacial behaviour between $\mathrm{Bi}_{1.5} \mathrm{ZnNb}_{1.5} \mathrm{O}_{7}$. $0.02 \mathrm{~V}_{2} \mathrm{O}_{5}$ and Ag. J. Eur. Ceram. Soc., 2003, 23, 2593-2596.

7. Lee, Y. C., Lin, C. H. and Lin, I. N., Bi-Zn-Nb-O microwave dielectric materials for multilayer filter application. Mater. Chem. Phys., 2003, 79, 124-128.

8. Wu, M. C., Huang, K. T. and Su, W. F., Microwave dielectric properties of doped $\mathrm{Zn}_{3} \mathrm{Nb}_{2} \mathrm{O}_{8}$ ceramics sintered below $950{ }^{\circ} \mathrm{C}$ and their compatibility with silver electrode. Mater. Chem. Phys., 2006, 98, 406-409.

9. Long, S., McAllister, M. and Liang, Shen., The resonant cylindrical dielectric cavity antenna. IEEE Trans. Antennas Propag., 1983, 31, 406-412.

10. Kishk, A. A., Ahn, B. and Kajfez, D., Broadband stacked dielectric resonator antennas. Electron. Lett., 1989, 25, 1232-1233.

11. Buerkle, A., Sarabandi, K. and Mosallaei, H., Compact slot and dielectric resonator antenna with dual-resonance, broadband characteristics. IEEE Trans. Antennas Propag., 2005, 9, 1020-1027.

12. Hsiao, F. R., Wang, C., Wong, K. L. and Chiou, T. W., Broadband veryhigh-permittivity dielectric resonator antenna for WLAN application. IEEE Antennas Propag. Int. Symp., 2002, 4, 490-493. 